\title{
Outcomes and factors associated with infant abusive head trauma in the US
}

\author{
Miriam Nuño, PhD, ${ }^{1}$ Lindsey Pelissier, PsyD,, Kunal Varshneya, ${ }^{1}$ Matthew A. Adamo, MD, ${ }^{2}$ and \\ Doniel Drazin, MD' \\ ${ }^{1}$ Center for Neurosurgical Outcomes Research, Maxine Dunitz Neurosurgical Institute, Department of Neurosurgery, \\ Cedars-Sinai Medical Center, Los Angeles, California; and '2Department of Neurosurgery, Albany Medical Center Hospital, \\ Albany, New York
}

\begin{abstract}
OBJECT Head trauma is the leading cause of death in abused children, particularly prior to the age of 2 years. An awareness of factors associated with this condition as well as with a higher risk of mortality is important to improve outcomes and prevent the occurrence of these events. The objective of this study was to evaluate outcomes and factors associated with poor outcomes in infants with diagnosed abusive head trauma (AHT). Patient characteristics, socioeconomic factors, and secondary conditions such as retinal bleeding, contusion, and fractures were considered.
\end{abstract}

METHODS Data were obtained from the Healthcare Cost and Utilization Project of the Agency for Healthcare Research and Quality. From the Kids' Inpatient Database (KID) sample, the authors identified infants no older than 23 months who had been diagnosed with AHT in 2000, 2003, 2006, and 2009. All statistical analyses were conducted in SAS 9.2. Descriptive statistics were provided, and multivariate logistic regression models were applied to evaluate factors associated with mortality and nonroutine discharge.

RESULTS A total of 5195 infants were analyzed in this study. Most infants (85.5\%) had ages ranging between 0 and 11 months and were male (61.6\%). Overall mortality was $10.8 \%$, with a rate of $9.8 \%$ in the 0 - to 11 -month-old cohort and $16.5 \%$ in the 12 - to 23 -month-olds ( $p=0.0003$ ). The overall nonroutine discharge rate of $25.6 \%$ increased significantly from $23.3 \%$ to $39.0 \%$ with increasing age $(0-11$ vs $12-23$ months of age, $p<0.0001)$. Assuming a multivariate model that adjusted for multiple confounders, the authors found that older infants (12-23 vs 0-11 months, OR $1.81,95 \% \mathrm{Cl} 1.18-$ 2.77 ) with a secondary diagnosis of retinal bleeding (OR 2.85, 95\% Cl 2.02-4.00) or shaken baby syndrome (OR 2.09, $95 \% \mathrm{Cl} 1.48-2.94)$ had an increased risk of mortality; these factors were similarly associated with an increased odds of a nonroutine discharge. A higher income $(\$ 30,001-\$ 35,000$ vs $\$ 1-\$ 24,999)$ was associated with a reduction in the odds of mortality (OR $0.46,95 \% \mathrm{Cl} 0.29-0.72)$. In the subset of cases (1695 [32.6\%]) that specified the perpetrator involved in infant injury, the authors found that the father, stepfather, or boyfriend was most frequently reported (67.4\%). A trend for a higher AHT incidence was documented in the early ages (peak at 2 months) compared with older ages.

CONCLUSIONS Despite the higher incidence of AHT among infants during the earlier months of life, higher mortality was documented in the 12- to 23-month-olds. Retinal bleeding and shaken baby syndrome were secondary diagnoses associated with higher mortality and nonroutine discharge. Males (67.4\%) were overwhelmingly documented as the perpetrators involved in the injury of these infants.

http://thejns.org/doi/abs/10.3171/2015.3.PEDS14544

KEY WORDS abusive head trauma; in-hospital mortality; non-routine discharge; fracture; contusion; hematoma; retina bleeding; shaken baby syndrome; perpetrator; confidence interval 
A CCORDING to data from the National Child Abuse and Neglect Data System (NCANDS), 49 states reported 1598 fatalities with a national estimate of 1640 child deaths from abuse and neglect in 2012. These figures equal a rate of 2.20 deaths per 100,000 children per year and an average of 4 children dying every day from abuse and neglect. ${ }^{29}$ The NCANDS also concluded that children younger than 1 year accounted for $44.3 \%$ of fatalities. The majority of child maltreatment deaths resulted from injuries to the head, otherwise known as abusive head trauma (AHT).

A policy statement issued by the American Academy of Pediatrics in 2009 supports the term "abusive head trauma" to describe inflicted injury in infants and children resulting from violent shaking, blunt impact, or a combination of both. ${ }^{6}$ The Centers for Disease Control and Prevention (CDC) defines AHT as an injury to the skull or intracranial contents of an infant or young child $(<5$ years of age) due to inflicted blunt impact and/or violent shaking. Exclusions to this definition include unintentional injuries resulting from neglectful supervision and gunshot wounds, stab wounds, and penetrating trauma. ${ }^{10}$ This terminology replaces the former denotation of "shaken baby syndrome" (SBS), as the former described only one mechanism of head injury.

Despite the specific definition of AHT, several challenges make tracking its occurrence difficult, including inconsistencies in defining it and variations in how these definitions are applied in multiple hospital settings. The CDC established guidelines for AHT in 2008 using the International Classification of Diseases (ICD-9) code for nonfatal AHT and more recently the ICD-10 codes for fatal cases. ${ }^{20}$ Additional limitations in documenting these cases include underreporting, lack of consistent standards for child autopsies or death investigations, uncoordinated nonmultidisciplinary investigations, and medical examiners lacking specific training in child abuse and neglect. Based on a retrospective chart review of head trauma cases, as many as $31 \%$ of cases of AHT were classified as missed according to Jenny et al. ${ }^{12}$ Thus, it is important to ensure that any patient with AHT is appropriately evaluated, documented, and coded. Despite the inaccuracies that may be involved in coding AHT cases, previous studies have reported potential risk factors for AHT in young children, including demographic, socioeconomic, and clinical. ${ }^{3,6,8,14}$ According to several studies, infants younger than 1 year and with a lower socioeconomic status are at higher risk for AHT.6,14 Additionally, a higher risk of AHT has been documented among specific racial and/or ethnic minorities. ${ }^{3,8}$ Clinical entities associated with AHT include retinal hemorrhages and subdural hematomas. ${ }^{9,28}$ Although pertinent information has been obtained from studies published to date, most of these studies have significant limitations, for example, small sample sizes, hospital-specific characteristics, and an inability to generalize findings to infants nationwide.

In the present study we aimed to evaluate outcomes and risk factors associated with AHT among infants of ages up to 23 months. We suspected that patient-specific factors such as age, income, and secondary conditions may be associated with prognosis. Although there has been limited reporting of the perpetrators involved in documented AHT cases, we provide a detailed description of the persons involved in these injuries. Overall, we hope that this study helps solidify and validate existing data on this patient population as reported in smaller studies. More importantly, however, we hope that these data help increase awareness by emphasizing factors that seem to be consistently associated with poor outcomes.

\section{Methods}

\section{Data Source and Patient Selection}

Data were obtained from the Healthcare Cost and Utilization Project of the Agency for Healthcare Research and Quality. ${ }^{13}$ Using the Kids' Inpatient Database (KID) sample, we identified infants of ages up to 23 months who had been diagnosed with AHT in 2000, 2003, 2006, and 2009. The KID is a nationally representative database that samples $80 \%$ of pediatric discharges and $10 \%$ of uncomplicated births to increase the statistical power to detect and evaluate rare conditions among hospitalized children. Discharges are weighted based on the sampling scheme to permit inferences for a nationally representative population. In 2009, the most recent year for which the KID was available at the time of this study, the KID contained deidentified information for 7.4 million weighted discharges from 4121 hospitals in 44 states. We used the narrow definition algorithm for ICD-9-CM and E codes developed by an AHT expert panel convened by the CDC (Table 1). ${ }^{20}$ Given our interest in the outcomes of patients with AHT, we opted for the narrow definition since it is considered more specific in its case ascertainment. Only infants younger than 24 months were included in this analysis.

\section{Data Variables}

A patient's age in months, along with sex, race, type of hospital admission (emergent/urgent, elective), insurance (private, self-pay), and median household income was documented. Note that a 1-month-old infant has an age ranging from 28 to 61 days.

Hospital-specific characteristics such as teaching versus nonteaching, children's versus nonchildren's hospital, and hospital region (Northeast, Midwest, South, West) were noted. Year of discharge and perpetrator involved in the AHT assault were documented. A detailed description of secondary diagnoses was made.

\section{Outcome Variables}

In-hospital mortality was the main outcome of interest. Secondarily, we explored nonroutine discharge events, which we denoted as a discharge other than a routine discharge (for example, transfers and home health care). Length of hospital stay and total charges accumulated during a hospitalization were also noted.

\section{Statistical Analysis}

A detailed description of the data is provided in terms of means, standard errors, medians, and interquartile ranges (IQRs). Predicted probabilities of mortality and $95 \%$ confidence intervals were calculated by age in months by 
TABLE 1. Algorithm for capturing definite or presumptive AHT cases using the narrow definition*

\begin{tabular}{ccc}
\hline ICD-9-CM Diagnosis Codes & $\begin{array}{c}\text { ICD-9-CM External Cause of Injury } \\
\text { or Abuse Code }\end{array}$ & \multicolumn{1}{c}{ Fall \& Accident Codes } \\
\hline $781.0-781.4,781.8,800.1-800.4,800.6-800.9,801.1-801.4$, & E960.0, E967, E968.1, E968.2, & E800-E807, E810-E819, E820-E825, E826- \\
$801.6-801.9,803.1-803.4,803.6-803.9,804.1-804.4$, & E968.8, E968.9, 995.50†, 995.54, & E829, E830-E838, E840-E845, E846-E848, \\
$804.6-804.9,850.0-850.9,851.0-851.99,852.0-852.59$, & $995.59 \dagger$ & E880-E888, E890-E899, E900-E909, \\
$853.0-853.19,854.0-854.19,950.0-950.3,995.55 \ddagger$ & & E910-E915, E916-E928 \\
\hline
\end{tabular}

\footnotetext{
* See Parker et al., 2012, for the CDC recommendations for capturing AHT in children.

$\dagger$ Excluded case in the presence of a fall or accident code.

$\ddagger$ Did not require a cause code.
}

using a univariate logistic regression model. Factors associated with mortality and nonroutine discharge at the univariate level (alpha 0.2) were considered in the adjusted multivariate logistic models. A p value $\leq 0.05$ was considered statistically significant. All statistical analyses were conducted in SAS 9.2 (SAS Institute Inc.).

\section{Results \\ Demographics}

A total of 5195 infants ages 0-23 months were diagnosed with AHT according to the KID (Table 2). The average age in months was 5.9 with a median of 3.5 (IQR 1.5-7.4). A preponderance of patients were male (61.6\%), and $49.6 \%$ of all patients were documented as white. Most cases were admitted as emergent or urgent $(92.7 \%)$ and had private insurance $(71.0 \%)$. Patients were relatively evenly spread among the documented median household income categories. A large fraction of patients were discharged from children's (79.7\%) and teaching (90.2\%) hospitals (Table 3). Fewer patients were diagnosed in northeastern hospitals $(12.3 \%)$ than in southern ones $(33.7 \%)$. A consistent proportion of AHT discharges were reported in 2000, 2003, 2006, and 2009.

\section{Age and Perpetrator Distribution}

A detailed plotting of the number of AHT cases by patient age in months reveals an increase in documented cases in the early months with a significant decrease as age increased (Fig. 1). The highest frequency (16.1\%) of cases was noted in 2-month-old infants, and the frequency was $6.9 \%$ rate among 5-month-olds and $1.4 \%$ in the 13 -monthold cohort. Of the 5195 documented AHT cases, 381 (7.3\%) had missing data on the perpetrator variable. Among the 4814 cases with a data on the perpetrator, the majority of cases (3119 [64.8\%]) indicated "other, unspecified" as the perpetrator of the injury (Fig. 2). Considering only those patients with a specific perpetrator indicated (1695 [32.6\%]), we found that father figures (father, stepfather, or boyfriend) were involved in $1142(67.4 \%)$ cases, followed by mother figures (mother, stepmother, girlfriend) in 260 (15.3\%) cases, and non-relative caregivers in 168 (9.9\%) cases; other family relatives (related child/sibling/grandparent) and spouses/partners were described in $106(6.2 \%)$ and $19(1.1 \%)$ of all cases, respectively.

\section{Outcomes}

Overall mortality rate was $10.8 \%$, with a rate of $9.8 \%$ in the 0 - to 11 -month-old cohort and $16.5 \%$ in the 12 - to 23 -month-olds $(\mathrm{p}=0.0003)$. The overall nonroutine discharge rate of $25.6 \%$ increased significantly from $23.3 \%$ to $39.0 \%$ with increasing age ( $0-11$ vs $12-23$ months of age, $p$ $<0.0001$; Table 4). The average hospital stay was 9.9 days with a median of 5.6 days and IQR of 2.4-11.7 days. The average total charges during hospitalization were $\$ 56,494$. A list of secondary diagnoses that have been described in association with AHT is provided in Table 4. The most

TABLE 2. Characteristics of 5195 infants diagnosed with AHT in US hospitals in 2000, 2003, 2006, and 2009

\begin{tabular}{|c|c|}
\hline Variable & No. \\
\hline \multicolumn{2}{|l|}{ Age in mos $^{*}$} \\
\hline $0-11$ & 4440 \\
\hline $12-23$ & 755 \\
\hline \multicolumn{2}{|l|}{ Average age in mos $\dagger$} \\
\hline Mean (SEM) & $5.9(0.14)$ \\
\hline Median (IQR) & $3.5(1.5-7.4)$ \\
\hline No. of males (\%) & $3198(61.6)$ \\
\hline \multicolumn{2}{|l|}{ Race (\%)‡ } \\
\hline White & $1988(49.6)$ \\
\hline Black & $828(20.7)$ \\
\hline Hispanic & $796(19.9)$ \\
\hline Other & $393(9.8)$ \\
\hline \multicolumn{2}{|l|}{ Admission type (\%)‡ } \\
\hline Emergent/urgent & $4154(92.7)$ \\
\hline Elective & $325(7.2)$ \\
\hline \multicolumn{2}{|l|}{ Primary payer (\%)‡ } \\
\hline Private & $3679(71.0)$ \\
\hline Self-pay & $1124(21.7)$ \\
\hline Other & $382(7.4)$ \\
\hline \multicolumn{2}{|c|}{ Median income in zip code (\%)‡ } \\
\hline$\$ 1-\$ 24,999$ & $1467(28.9)$ \\
\hline$\$ 25,001-\$ 30,000$ & $1493(29.4)$ \\
\hline$\$ 30,001-\$ 35,000$ & $1278(25.2)$ \\
\hline$\$ 35,001 \&$ above & $840(16.5)$ \\
\hline \multicolumn{2}{|c|}{$\begin{array}{l}\text { * In patients without a precise age in months, an age-year of } 0 \text { corresponded } \\
\text { to an age of } 0-11 \text { months and an age-year of } 1 \text { corresponded to an age of } \\
12-23 \text { months. } \\
\text { † Data available in } 4249(81.8 \%) \text { of cases. } \\
\text { } \text { Missing data }(\%) \text { : sex }(0.06) \text {, race }(22.9) \text {, admission type }(13.8 \%) \text {, payer } \\
(0.2) \text {, and income }(2.2) \text {. } \\
\S \text { Medicare is included in other. }\end{array}$} \\
\hline
\end{tabular}

J Neurosurg Pediatr Volume 16 • November 2015 
TABLE 3. Hospital-specific characteristics of 5195 infants diagnosed with AHT in US hospitals in 2000, 2003, 2006, and 2009

\begin{tabular}{cc}
\hline Variable & No. (\%) \\
\hline Children's hospital $^{*}$ & $3777(79.7)$ \\
\hline Teaching hospital $^{*}$ & $4367(90.2)$ \\
\hline Hospital region $^{*}$ & $642(12.4)$ \\
\hline Northeast & $1424(27.4)$ \\
\hline Midwest & $1749(33.7)$ \\
\hline South & $1380(26.6)$ \\
\hline West & \\
\hline Year of discharge & $1212(23.3)$ \\
\hline 2000 & $1370(26.4)$ \\
\hline 2003 & $1299(25.0)$ \\
\hline 2006 & $1314(25.3)$ \\
\hline 2009 &
\end{tabular}

* Missing data (\%): children's hospital (8.8), teaching hospital (6.8).

common co-occurring diagnosis was subdural hematoma (60.1\%), followed by retinal hemorrhage (51.0\%), fracture (42.6\%), SBS (42.1\%), and contusion (17.4\%). Among patients with a diagnosed hematoma, $61.0 \%$ also had retinal hemorrhage, $17.4 \%$ had contusion, $24.7 \%$ had fracture, and $44.8 \%$ had SBS. The predicted probability of mortality increased by an average of $0.006 \%$ with an increasing age in months $\left(\mathrm{R}^{2}=0.43\right.$; Fig. 3$)$. A 1-sided Cochran-Armitage trend test also supported an increasing mortality trend with increasing age in months $(\mathrm{p}<0.0001)$.

In-hospital mortality and nonroutine discharge were evaluated while adjusting for multiple confounder factors (Table 5). We found that older infants (12-23 vs 0-11 months), a lower income, and additional diagnoses such as retinal hemorrhage and SBS were strongly associated with greater odds of mortality. The odds of mortality nearly doubled for infants of $12-23$ versus $0-11$ months (OR 1.81, 95\% CI 1.18-2.77). Infants from higher-income homes $(\$ 30,001-\$ 35,000)$ had a significant reduction in the odds of mortality compared with infants from the lowest-income homes (\$1-\$24,999; OR 0.46, 95\% CI 0.29-0.72). Retinal hemorrhage (OR 2.85, 95\% CI 2.02-4.00) and SBS (OR 2.09, 95\% CI 1.48-2.94) diagnoses were significantly associated with an increased odds of mortality.

In a subset analysis of mortality according to the perpetrator involved in the injury, we found that infants cared for by nonrelative caregivers had the highest mortality rate $(16.1 \%)$, followed by father, stepfather, or boyfriend (12.4\%), and mother, stepmother, or girlfriend (8.9\%).

\section{Discussion}

Using a national database, we were able to validate previous findings such as the correlation of age with the number of reported cases, where younger infants (0-11 months) were more commonly AHT victims than 12- to 23-month-olds. ${ }^{29-21,23,24}$ As in previous studies, we found that fathers, stepfathers, and boyfriends were most frequently reported as the perpetrator of injuries. Fewer cases occurred in northeastern hospitals than in the West, Midwest, and South. A possible explanation for the differing rates in reported cases by state may be the varying levels of AHT awareness. Kesler et al. and Altman et al. reported a greater concentration of AHT prevention programs in the northern states. ${ }^{1,15}$ As noted in Shanahan et al., it is also possible that differences in ICD-9-CM coding practices affect the rates reported by authors using administrative databases. ${ }^{25}$ In a preliminary exploration of the KID database, we found that northern states were much more likely to document SBS than western states $(54.8 \%$ vs $35.0 \%$, p $=0.004)$. Other possible explanations for the differences in

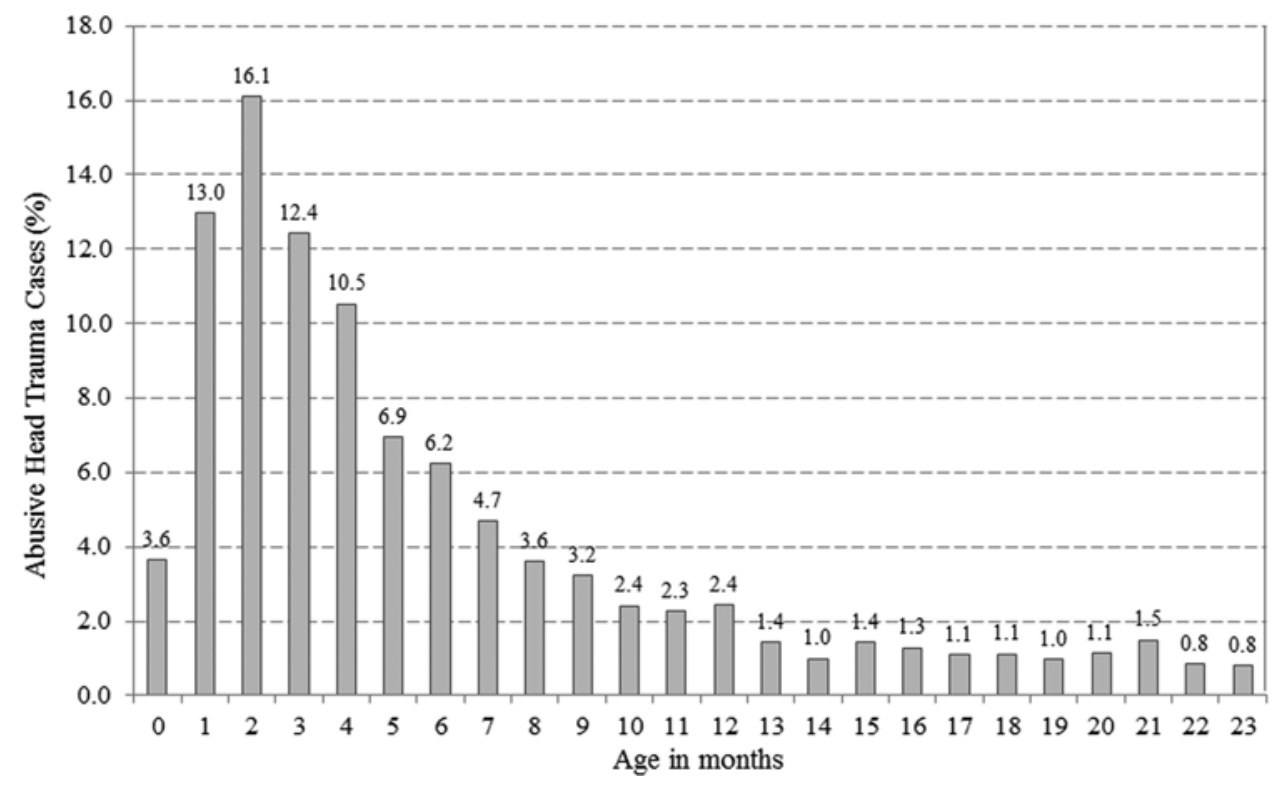

FIG. 1. Distribution of AHT cases diagnosed in US hospitals $(2000,2003,2006$, and 2009) by patient age in months, based on a total of 4249 patients with available data. 


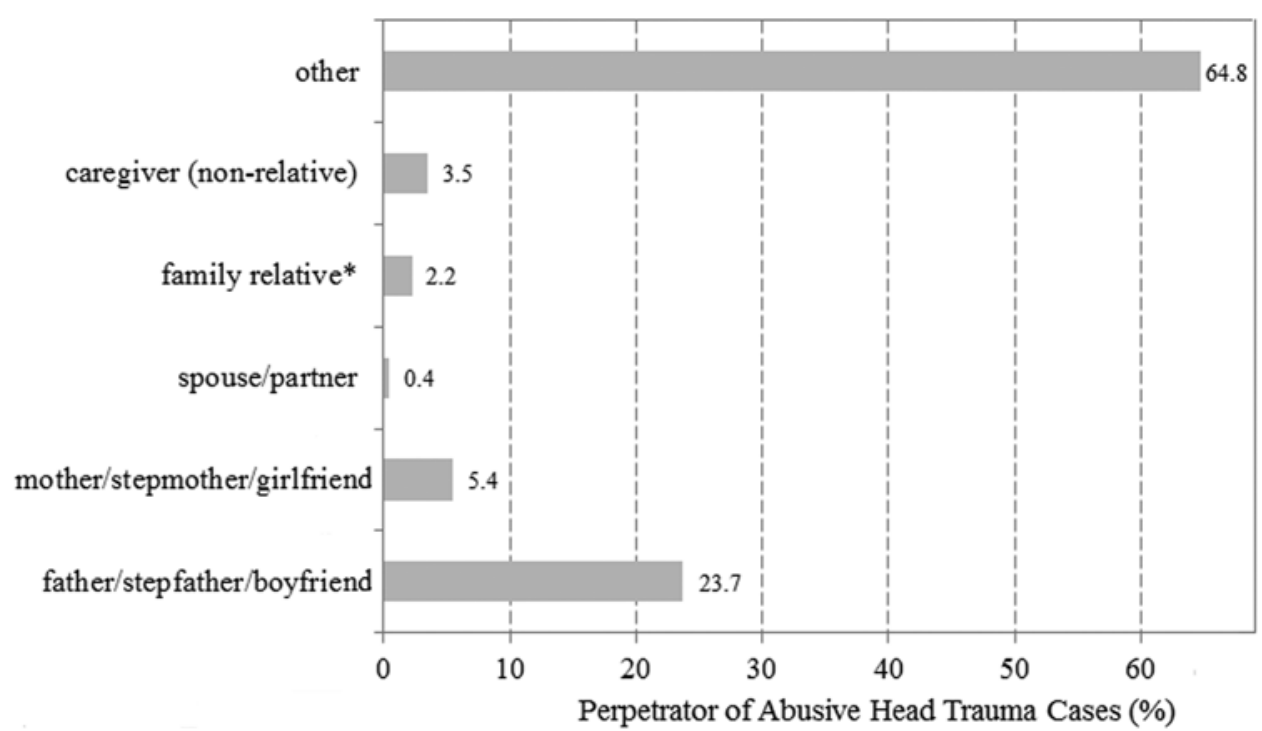

FIG. 2. Frequency of perpetrators involved in the 4818 documented AHT cases diagnosed in US hospitals in 2000, 2003, 2006, and 2009. "Other" refers to cases in which the perpetrator was indicated as "other, unspecified." *Relative includes related child/ sibling/grandparent.

reported cases may be other external factors such as economy or unemployment, which can vary across regions. Also in this study we determined that the odds of mortality were higher in infants secondarily diagnosed with retinal hemorrhage and SBS and in patients from lowerincome households. These findings are in accordance with previously reported trends. ${ }^{6,9,14,28}$ The reporting of secondary diagnoses such as SBS and retinal hemorrhage provides some insight, although limited, on the mechanism of injury and clinical features, respectively.

However, the novel finding in our study is that the odds of mortality increased for infants older than 12 months. A possible explanation for this observation may be the fact that older children have smaller or closed fontanelles, as well as sutures that are less mobile (sutures do not really close until age 18 years or so when the skull stops growing), making it more difficult for the cranial vault to accommodate increases in intracranial pressure. Furthermore, fluctuations in mean arterial pressure beyond either end of their normal range lead to alterations in cerebral blood flow and contribute to ischemia or disruption of the blood-brain barrier. This phenomenon may lead to worse outcomes for the older infants who could potentially have higher fluctuations. Another explanation for the increased risk of mortality captured in the older cohort may be the cumulative effects of AHT that are more likely to be prominent at an older age. Further clinical findings in our study revealed that retinal hemorrhages and SBS were independently associated with increased odds of mortality. According to Levin et al. and others, retinal hemorrhage was more common in children who died of AHT than in neurologically intact survivors because of their nonsuperficial nature; it is a common symptom of severe trauma and is less often reported in accidental cases $(0 \%-8 \%))^{6,13,18,22}$ The shaking of a child is usually described by perpetrators as an attempt to stop an infant's excessive crying, but it can cause significant intracranial trauma and whiplash. ${ }^{11}$
Frustrated parents often use shaking as a means of quieting an infant, and reports of excessive crying at approximately 2 months of age coincide with documented cases of SBS. $5,16,20,26$

Beyond clinical findings, familial socioeconomic status and perpetrator identity impact the mortality risk. Data in this study corroborate results in other studies indicating a majority of socioeconomically disadvantaged families among cases of AHT., ${ }^{2,6,14}$ Potential theories for this finding may be the higher rates of all physical abuse in patients on Medicaid and a higher proportion of children on Medicaid having abusive injuries rather than accidental injuries..$^{19}$ Limited or delayed access to health care may also partially explain the increased risk of mortality

TABLE 4. Outcomes of infants diagnosed with AHT in US hospitals in 2000, 2003, 2006, and 2009

\begin{tabular}{cc}
\hline Outcomes & No. $(\%)$ \\
\hline Mortality & $560(10.8)$ \\
\hline Nonroutine discharge* & $1328(25.6)$ \\
\hline Length of stay in days $^{*}$ & $9.9(0.31)$ \\
\hline Mean (SE) & $5.6(2.4-11.7)$ \\
\hline Median (IQR) & \\
\hline Total charges (\$) & $\$ 56,494(\$ 2825)$ \\
\hline Mean (SE) & $\$ 28,917(\$ 13,454-\$ 67,986)$ \\
\hline Median (IQR) & $2214(42.6)$ \\
\hline Secondary diagnoses & $905(17.4)$ \\
\hline Fracture & $3122(60.1)$ \\
\hline Contusion & $2652(51.0)$ \\
\hline Hematoma & $2186(42.1)$ \\
\hline Retinal bleeding &
\end{tabular}

* Nonroutine discharge includes transfers/home health care. 


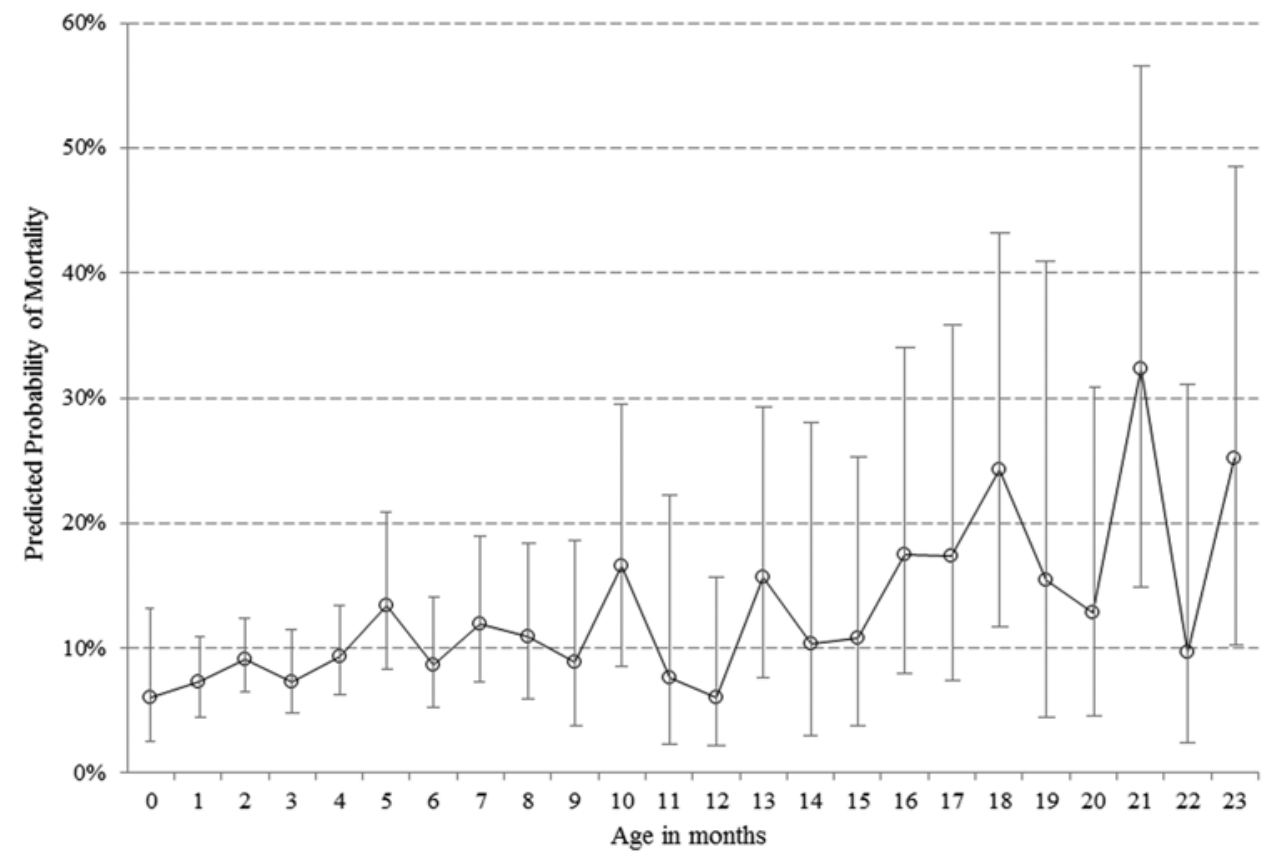

FIG. 3. Predicted probability of mortality and $95 \%$ confidence intervals by age in months for cases diagnosed in US hospitals $\left(2000,2003,2006\right.$, and 2009). Trend line for a linear fit resulted in $y=0.006 x+0.0546\left(R^{2}=0.4305\right)$.

documented in socioeconomically disadvantaged patients. In addition to this study, previous research has included discussions on the prevalence of a nonparental perpetrator or the father figure as the main abuser.,23,27 However, throughout the literature there is a significant discrepancy in the rate of abuse attributed to nonparental perpetrators or father figures because of the lack of accurate reporting on the perpetrator given the potential legal consequences.
Yet the fact that these perpetrators seem to be associated with an increased risk of mortality emphasizes the importance of further investigation. A possible explanation for this increased mortality risk is that nonparental caregivers and father figures are less likely to be involved in routine doctor examinations and less aware of pertinent information delivered by clinicians. ${ }^{27}$ Thus, fathers may not have information on how to manage behavioral problems in

TABLE 5. Adjusted odds ratios for mortality and nonroutine discharge

\begin{tabular}{|c|c|c|c|c|c|c|}
\hline \multirow[b]{2}{*}{ Variables* } & \multicolumn{3}{|c|}{ In-Hospital Mortality } & \multicolumn{3}{|c|}{ Nonroutine Discharge } \\
\hline & OR & $95 \% \mathrm{Cl}$ & $p$ Value & OR & $95 \% \mathrm{Cl}$ & $\mathrm{p}$ Value \\
\hline \multicolumn{7}{|l|}{ Age in mos } \\
\hline $12-23$ vs $0-11$ & 1.81 & $1.18-2.77$ & 0.006 & 2.24 & $1.58-3.16$ & $<0.0001$ \\
\hline Race (ref: white) & & & 0.61 & & & 0.04 \\
\hline Black & 1.10 & $0.72-1.58$ & & 1.61 & $1.15-2.24$ & \\
\hline Hispanic & 1.08 & $0.72-1.64$ & & 1.17 & $0.82-1.67$ & \\
\hline Other & 1.36 & $0.86-2.14$ & & 1.14 & $0.78-1.69$ & \\
\hline Insurance (ref: non-private) & & & 0.18 & & & 0.42 \\
\hline Private & 0.71 & $0.43-1.17$ & & 0.88 & $0.65-1.19$ & \\
\hline Admission (ref: non-elective) & & & 0.23 & & & 0.45 \\
\hline Elective & 0.65 & $0.33-1.31$ & & 0.86 & $0.57-1.29$ & \\
\hline Income (ref: \$1-\$24,999) & & & 0.006 & & & 0.45 \\
\hline$\$ 25,001-\$ 30,000$ & 0.69 & $0.48-1.00$ & & 0.82 & $0.61-1.11$ & \\
\hline$\$ 30,001-\$ 35,000$ & 0.46 & $0.29-0.72$ & & 0.82 & $0.60-1.13$ & \\
\hline$\$ 35,001 \&$ above & 0.76 & $0.46-1.26$ & & 0.99 & $0.69-1.44$ & \\
\hline \multicolumn{7}{|l|}{ Additional conditions } \\
\hline Retinal bleeding & 2.85 & $2.02-4.00$ & $<0.0001$ & 1.70 & $1.34-2.17$ & $<0.0001$ \\
\hline SBS & 2.09 & $1.48-2.94$ & $<0.0001$ & 1.98 & $1.58-2.48$ & $<0.0001$ \\
\hline
\end{tabular}

* Factors significant at the 0.2 level in the univariate model were included. 
children, leading them to engage in acting out behaviors and ultimately impulsive physical abuse resulting in AHT.

While some of the strengths of this study relate to the large sample size that facilitates the evaluation of nationwide trends and hospital-level characteristics, there are several limitations that are inherent to administrative databases. The most important limitation is the accuracy of ICD-9 codes for the diagnosis of physical abuse; for example, there is a lack of detailed documentation on the severity of retinal hemorrhage, which has been shown to be associated with an increased likelihood of child abuse. ${ }^{4}$ The high rate of missing documentation on the perpetrators of injury in the cases discussed in this study is a limitation and is possibly found in small cohort studies given the sensitivity and implications of these data.

We described some findings that can be used to improve the practice of neurosurgeons caring for infants at risk for AHT. In addition to validating the trends in mortality according to age, income, and secondary diagnoses, we highlighted patient and hospital-specific factors associated with an increased risk of AHT.

Our data showed that males (father/stepfather/boyfriend) were the main perpetrators of injury in the reported cases. We speculate that limited AHT awareness and/or differences in socioeconomic factors in the southern states may be associated with higher rates of AHT. While we were unable to document any delays in the diagnosis or treatment of reported AHT cases, previous studies have noted significant rates of misclassification $(31 \%)$ of these cases. ${ }^{12}$ Although patients were eventually classified correctly, there was certainly a delay in documentation and appropriate treatment. Given the described trends in incidence and risk, we are confident that neurosurgeons caring for infants with injuries resembling the conditions described herein (AHT, SBS, retinal hemorrhage, fractures, and hematomas) could take an active role in documenting data that are typically missing. Furthermore, efforts to increase awareness in the clinic through the discussion of factors associated with AHT (age, perpetrator, socioeconomic factors) among family members of patients who may be at risk could play a critical role in improving outcomes in this patient population.

\section{Conclusions}

In infants diagnosed with AHT, an older age, lower income, and secondary diagnoses such as retinal hemorrhage and SBS were significantly associated with an increased risk of mortality. Abusive head trauma cases were most often reported in infants in the early months of life, peaking at 2 months. In the cases with documented perpetrators, we found that infants attended by non-relative caregivers had the greatest risk of mortality, followed by fathers, stepfathers, and boyfriends.

\section{References}

1. Altman RL, Canter J, Patrick PA, Daley N, Butt NK, Brand DA: Parent education by maternity nurses and prevention of abusive head trauma. Pediatrics 128:e1164-e1172, 2011

2. Bechtel K, Stoessel K, Leventhal JM, Ogle E, Teague B, Lavietes S, et al: Characteristics that distinguish accidental from abusive injury in hospitalized young children with head trauma. Pediatrics 114:165-168, 2004

3. Bennett MD Jr, Hall J, Frazier L Jr, Patel N, Barker L, Shaw K: Homicide of children aged 0-4 years, 2003-04: Results from the National Violent Death Reporting System. Inj Prev 12 (Suppl 2):ii39-ii43, 2006

4. Binenbaum G, Mirza-George N, Christian CW, Forbes BJ: Odds of abuse associated with retinal hemorrhages in children suspected of child abuse. J AAPOS 13:268-272, 2009

5. Blumenthal I: Shaken baby syndrome. Postgrad Med J 78:732-735, 2002

6. Christian CW, Block R: Abusive head trauma in infants and children. Pediatrics 123:1409-1411, 2009

7. Dias MS, Smith K, DeGuehery K, Mazur P, Li V, Shaffer ML: Preventing abusive head trauma among infants and young children: a hospital-based, parent education program. Pediatrics 115:e470-e477, 2005

8. Drake B, Jolley JM, Lanier P, Fluke J, Barth RP, Jonson-Reid M: Racial bias in child protection? A comparison of competing explanations using national data. Pediatrics 127:471478, 2011

9. Fanconi M, Lips U: Shaken baby syndrome in Switzerland: results of a prospective follow-up study, 2002-2007. Eur J Pediatr 169:1023-1028, 2010

10. Gordy C, Kuns B: Pediatric abusive head trauma. Nurs Clin North Am 48:193-201, 2013

11. Hadley MN, Sonntag VK, Rekate HL, Murphy A: The infant whiplash-shake injury syndrome: a clinical and pathological study. Neurosurgery 24:536-540, 1989

12. Jenny C, Hymel KP, Ritzen A, Reinert SE, Hay TC: Analysis of missed cases of abusive head trauma. JAMA 281:621626, 1999

13. Johnson DL, Braun D, Friendly D: Accidental head trauma and retinal hemorrhage. Neurosurgery 33:231-235, 1993

14. Keenan HT, Runyan DK, Marshall SW, Nocera MA, Merten DF, Sinal SH: A population-based study of inflicted traumatic brain injury in young children. JAMA 290:621-626, 2003

15. Kesler H, Dias MS, Shaffer M, Rottmund C, Cappos K, Thomas NJ: Demographics of abusive head trauma in the Commonwealth of Pennsylvania. J Neurosurg Pediatr 1: 351-356, 2008

16. Kivlin JD: Manifestations of the shaken baby syndrome. Curr Opin Ophthalmol 12:158-163, 2001

17. Leventhal JM, Gaither JR: Incidence of serious injuries due to physical abuse in the United States: 1997 to 2009. Pediatrics 130: $847-\mathrm{e} 852,2012$

18. Levin AV: Retinal hemorrhage in abusive head trauma. Pediatrics 126:961-970, 2010

19. Palusci VJ, Covington TM: Child maltreatment deaths in the U.S. National Child Death Review Case Reporting System. Child Abuse Negl 38:25-36, 2014

20. Parks SE, Kegler SR, Annest JL, Mercy JA: Characteristics of fatal abusive head trauma among children in the USA: 2003-2007: an application of the CDC operational case definition to national vital statistics data. Inj Prev 18:193-199, 2012

21. Risen SR, Suskauer SJ, Dematt EJ, Slomine BS, Salorio CF: Functional outcomes in children with abusive head trauma receiving inpatient rehabilitation compared with children with nonabusive head trauma. J Pediatr 164:613-619, 2014

22. Schloff S, Mullaney PB, Armstrong DC, Simantirakis E, Humphreys RP, Myseros JS, et al: Retinal findings in children with intracranial hemorrhage. Ophthalmology 109:1472-1476, 2002

23. Scribano PV, Makoroff KL, Feldman KW, Berger RP: Association of perpetrator relationship to abusive head trauma clinical outcomes. Child Abuse Negl 37:771-777, 2013

24. Selassie AW, Borg K, Busch C, Russell WS: Abusive head 
trauma in young children: a population-based study. Pediatr Emerg Care 29:283-291, 2013

25. Shanahan ME, Zolotor AJ, Parrish JW, Barr RG, Runyan DK: National, regional, and state abusive head trauma: application of the CDC algorithm. Pediatrics 132:e1546-e1553, 2013

26. Spaide RF, Swengel RM, Scharre DW, Mein CE: Shaken baby syndrome. Am Fam Physician 41:1145-1152, 1990

27. Starling SP, Holden JR, Jenny C: Abusive head trauma: the relationship of perpetrators to their victims. Pediatrics 95:259-262, 1995

28. Talvik I, Metsvaht T, Leito K, Põder H, Kool P, Väli M, et al: Inflicted traumatic brain injury (ITBI) or shaken baby syndrome (SBS) in Estonia. Acta Paediatr 95:799-804, 2006

29. US Department of Health and Human Services: Child Maltreatment 2013. Washington, DC: US Dept of Health and Human Services, 2015

\section{Author Contributions}

Conception and design: Nuño. Acquisition of data: Nuño. Analysis and interpretation of data: Nuño. Drafting the article: Nuño, Pelissier, Varshneya, Drazin. Critically revising the article: all authors. Reviewed submitted version of manuscript: all authors. Approved the final version of the manuscript on behalf of all authors: Nuño. Statistical analysis: Nuño. Administrative/techni$\mathrm{cal} /$ material support: Nuño. Study supervision: Nuño.

\section{Correspondence}

Miriam Nuño, Center for Neurosurgical Outcomes Research, Department of Neurosurgery, Cedars-Sinai Medical Center, Advanced Health Sciences Pavilion, 127 S. San Vicente Blvd., Ste. A6229, Los Angeles, CA 90048.email: miriam.nuno@cshs. org. 